\title{
Article \\ Place Narratives and the Experience of Class: Comparing Collective Destigmatization Strategies in Two Social Housing Neighborhoods
}

\author{
Lotta Junnilainen \\ Faculty of Social Sciences, Tampere University, 33014 Tampere, Finland; E-Mail: lotta.junnilainen@tuni.fi
}

Submitted: 26 August 2019 | Accepted: 19 December 2019 | Published: 27 February 2020

\begin{abstract}
A growing body of literature has investigated the various ways in which residents of stigmatized neighborhoods respond to and cope with stigmatization. However, these approaches have fallen short in tackling the question of how particular places shape responses to stigmatization. In this article, I take seriously the question of context and, based on a comparative ethnography of two social housing neighborhoods in Finland, show how residents in similar social structural positions differed in terms of the cultural milieus they inhabited, presenting them with different cultural resources for dealing with stigmatization. In the article, I suggest that non-recognition is an understudied but significant consequence of stigma related to social housing neighborhoods. Further, I suggest that depending on the historical and cultural context of the neighborhood, different destigmatization strategies are employed when residents face non-recognition. My data shows that locally lived collective place narratives informed residents' experiences of class: In one neighborhood, the defining element of the locally acknowledged place narrative was class struggle, whereas in the other it was middle-class aspiration. These narratives served as building blocks for their destigmatization strategies.
\end{abstract}

\section{Keywords}

class; culture; destigmatization; ethnography; housing; non-recognition; place narrative; social housing; stigma; territorial stigma

\section{Issue}

This article is part of the issue "New Research on Housing and Territorial Stigma" edited by Margarethe Kusenbach (University of South Florida, USA) and Peer Smets (Vrije Universiteit Amsterdam, the Netherlands).

(C) 2020 by the author; licensee Cogitatio (Lisbon, Portugal). This article is licensed under a Creative Commons Attribution 4.0 International License (CC BY).

\section{Introduction}

A growing body of literature has investigated the various ways in which members of stigmatized groups respond to and cope with stigmatization (Lamont, 2018; Lamont \& Mizrachi, 2012; Moon, 2012) and more specifically territorial or housing stigma (August, 2014; Garbin \& Millington, 2012; Kirkness, 2014; Kusenbach, 2013; Queirós \& Pereira, 2018; Slater \& Anderson, 2012; Wacquant, 2007, 2008). It has been argued that stigmatization is not a straightforward process whereby residents simply internalize negative representations of their neighborhoods; rather, they have various social and strategic tools for coping with, responding to and resisting stigma (Kirkness, 2014). The propensity to adopt this tool or that has been said to depend on individual dif- ferences in access to personal, social and economic resources which mitigate the negative effects of stigmatization (Link \& Phelan, 2001, p. 380), as well as on one's position and trajectory in social and physical space (Wacquant, 2011). However, focusing on the individual level, these approaches have fallen short in tackling the question of how places shape responses to stigmatization. Do different neighborhoods enable and constrain responses similarly, or are there context-specific differences? Given the academic consensus on the heterogeneity of poor neighborhoods and their varying effects on residents (Sharkey \& Faber, 2014), we should not assume meso-level (Fine, 2012) strategies for coping with stigma to be context free either. Queirós and Pereira (2018) have recently stated the importance of collective work in confronting stigmatization in residential contexts 
but focus only on more formal forms of resistance. In this article, by contrast, I argue that focus on everyday resistance (Scott, 1985) is the key to seeing how localities, identifications and collective destigmatization strategies work together.

Using ethnographic data from Steephill ${ }^{1}$ and Fireweed Village, two social housing neighborhoods in Finland, I illustrate the power of place narratives (BrownSaracino, 2015) as cultural tools or social imaginaries (Reed, 2017, p. 32) that lead residents to interpret and act in the world in a certain way. I show how residents in similar social structural positions possessed different cultural resources for dealing with stigmatization (Lamont \& Mizrachi, 2012), depending on their neighborhood milieu. In one neighborhood, the defining element of the locally acknowledged place narrative was "class struggle," whereas in the other it was "middle-class aspiration." These narratives, as I will suggest, served as resources for collective destigmatization strategies employed by residents when faced with practices of non-recognition that, I assert, are the concrete but often unnoticed consequences of housing stigma.

The article contributes to the literature on cultural understandings of place and community, which recent approaches have seen grow in strength (Blokland, 2017; Borer, 2006; Brown-Saracino, 2011). Focusing on the understudied question of how the urban poor attempt to construct a meaningful living space and sense of selfworth and dignity in their lives (Gotham \& Brumley, 2002, p. 268) the article sheds light on the locally constructed cultural repertoires people can turn to and mobilize to make sense of their experiences (Lamont \& Mizrachi, 2012). Comparison of practices of "being-togetherness" (Binken \& Blokland, 2013, p. 294) in two social housing estates allows us to see stigmatized low-income neighborhoods not only as containers of the numerous negative effects of poverty, but also as historically and culturally diverse milieus that residents collectively draw on in order to gain recognition.

\section{Theoretical Approach and Literature Review}

\subsection{Stigmatization of Housing, Territory and Class}

It seems that in most Western countries living in a social housing estate is a stigmatizing position (Wassenberg, 2004). Residents of these social housing estates often suffer from stigma that is a multidimensional construct (Link \& Phelan, 2001; Pescosolido \& Martin, 2015). I note three forms of stigmatization that are relevant to the scope of this article. First, social housing residents routinely deal with what has been called "housing stigma" (Blokland, 2008; Hastings, 2004; Palmer, Ziersch, Arthurson, \& Baum, 2004; Slater, 2018; Vassenden \& Lie, 2013). Especially in nations where homeownership is the norm and a strong marker of social and moral status, social housing is associated with social pathologies. Finland in this respect is an illustrative context, since it has been described as a country of homeowners in which housing policy serves to assist those who fail to secure accommodation on the open market by providing them with social housing (Hyötyläinen, 2019; Ruonavaara, 1996). Accordingly, this type of housing then is associated with marginalized people and perceived as a form of social assistance. Social housing is housing "not for normal people" (Hyötyläinen, 2019, p. 53).

Second, social housing in Finland, as in many other countries, has been located in peripheral housing estates (Hyötyläinen, 2019) that suffer from territorial stigma (Wacquant, 2008). In Europe, the declining workingclass neighborhoods that have been impacted by deindustrialization and the fragmentation of wage labor, are in Wacquant's $(2007$, p. 67) words often "isolated and bounded territories increasingly perceived by both outsiders and insiders as social purgatories." A great deal of criticism based on empirical work has been directed at this statement, arguing that internal and external neighborhood images are two different things (see Wacquant, Slater, \& Pereira, 2014; Wassenberg, 2004). Nevertheless, neighborhoods tainted by "the blemish of place" (Wacquant, 2007) might be able to cope with the stigma, even resist it; but their chances of escaping it entirely are negligible.

Third, both housing and territorial stigma feed upon, strengthen and reproduce existing inequalities of class (Mckenzie, 2015; Skeggs, 2004). Class stigma relates to what Wacquant (2008, p. 30) has described as "the curse of being poor in the midst of a rich society in which participation in the sphere of consumption has become sine qua non of social dignity-a passport to personhood." Urban residents living at the bottom of the class structure in stigmatized neighborhoods are thus affected by multidimensional forms of territorial, housing and class stigma. Consequently, their position exposes them to relatively high "stigma consciousness" (Pinel, 1999), meaning constant fear for multiple reasons of being looked down on and devalued.

\subsection{Non-Recognition as Everyday Experience of Stigma}

In their everyday lives, residents of stigmatized neighborhoods are often misrecognized as lazy, immoral, violent or whatever stereotype outsiders employ to separate "them" from "us" (Link \& Phelan, 2001, p. 370). As Lamont, Beljean, and Clair (2014, p. 12) have stated, stigmatization as a social process shapes everyday interactions and easily results in consequences that contribute to the unequal distribution of recognition-"the fact of being acknowledged and given validation, legitimacy, value, worth, dignity and cultural membership." With respect to stigmatized housing, being deprived of recognition is normally understood as misrecognition. Much less research has focused on non-recognitioneffectively "being rendered invisible" (Fraser, 1997,

\footnotetext{
${ }^{1}$ All the names of places and people are pseudonyms for reasons of confidentiality.
} 
p. 14). In this article, I show how residents of social housing neighborhoods were deprived of their sense of coownership of place (Brown-Saracino, 2011) and in this regard collectively bypassed. From this, I suggest that in contrast with findings from previous studies, stigmatization may entail these subtle forms of non-recognition that residents need to negotiate. As Mckenzie (2015, pp. 8-9) has argued, non-recognition becomes especially relevant when examining class inequality, since feelings of invisibility have been noted as being one of the most common experiences in a class relations context. Thus, in this article I aim to understand stigma as a lived everyday experience which-in the context of social housing neighborhoods - takes the form of non-recognition. It is not obvious when people are being bypassed and approached as irrelevant, but we should at least try to see when it happens and how, since this is one of the ways "stigma power" (Link \& Phelan, 2014; Tyler \& Slater, 2018) operates.

\subsection{Place Narratives as Resources for Collective Destigmatization Strategies}

A growing literature has acknowledged that residents living in stigmatized social housing neighborhoods are not helpless victims who end up internalizing the negative image of their neighborhood, but actors drawing on a multiplicity of strategies to resist, manage and cope with it (e.g., Arthurson, Darcy, \& Rogers, 2014; August, 2014; Gotham \& Brumley, 2002; Kirkness, 2014; Pereira \& Queirós, 2014). Most of the research considering destigmatization strategies has focused on rhetorical and strategic tools deployed by individual members of stigmatized groups in reaction to perceived stigmatization (Pereira \& Queirós, 2014; Wacquant, 2007). At the collective level, studies have argued that contrary to general assumptions, residents living in stigmatized territories often experience belonging and attachment to their neighborhood (August, 2014; Jensen \& Christensen, 2012; Kirkness, 2014). However, understanding of neighborhoods as culturally significant, varied and collectively produced places (see Borer, 2006) in this literature has remained scarce. First, we lack a nuanced understanding of how and why residents' experiences and place attachments in different neighborhoods of an ostensibly similar social class background might vary (Cole, 2013, p. 66). Second, we know surprisingly little about how these experiences are lived and attachments come about in social practice (see Blokland, 2017). Simply put, we should not just study what people say, but focus on what they do (Jerolmack \& Khan, 2018).

My point of departure is the work of Lamont and her colleagues (see Lamont \& Mizrachi, 2012; Lamont et al., 2016) who have noted that responses to stigmatization vary across contexts depending on the locally available cultural resources people can employ to make sense of the world around them and thus strive at recognition. In their comparative work, Lamont et al. (2016) have fo- cused on cross-national explorations concerning cultural repertoires that serve as resources for destigmatization. Here, I focus on cultural resources available at the neighborhood level by studying place narratives. The idea of the term narrative is that people tend to tell stories, and through them develop an understanding of themselves, their lives and environments, and other factors that shape their actions (Somers, 1994). As Lamont and Small $(2008$, p. 84 ) have stated, the narrative perspective is particularly useful in showing that action is not an automatic response to a stimulus but is made possible within the context of narratives around which people make sense of their lives.

With respect to neighborhoods, narratives are historically informed collective processes of place-making that, once dominant in a public discourse, affect what defines "the community" and what does not (Blokland, 2009 , p. 1594). Brown-Saracino $(2015$, p. 41 ) has pinpointed place narratives as influential meso-level narratives providing models of who and how one should be in a local context. In practical terms, place narratives inform understandings of what kind of a place this is, what kind of people are living here and how people like "us" live. Of course, these narratives are not shared by everyone in the community. The focus of this article, however, is not on erasures and absent agents (Blokland, 2009), but on the idea of place narratives as practices through which residents interpret the stigmatized positions they are in. Approaching these narratives as cultural imaginaries that lead residents to interpret and act in the world in a certain way (Reed, 2017, p. 32), we can begin to understand them as resources for collective destigmatization strategies. These strategies, I will suggest, become identifiable in a comparative research setting relying on ethnographic methods.

\section{Context and Methods}

This article is based on the wide range of data sources collected for my ethnographic study of two social housing neighborhoods in Finland (Junnilainen, 2019). The study investigated what it means to live in neighborhoods that in the 1960s were burgeoning areas for working-class families but have now become places of concentrated disadvantage. This article is based on my empirical findings, which suggest that, first, stigmatization as an everyday experience also takes the form of non-recognition, and second, that neighborhood-specific place narratives serve as resources for collectively employed destigmatization strategies.

Steephill and Fireweed Village are located in two of the biggest cities in Finland: Helsinki and Turku. The municipality of Helsinki is the owner of Steephill, managing the housing stock through a city-owned housing company. The ownership and maintenance of Fireweed Village is organized through a housing company owned by the municipality of Turku in association with a couple of non-profit corporations. Both are prefabricated 
high-rise areas built in the 1960s at a time of rapid urbanization in Finland. The neighborhoods were built for working-class families in need of decent housing, and just like most suburban housing estates in Finland, are situated in peripheral areas on urban fringes. The neighborhoods are both state subsidized rental housing areas, where tenants are chosen on the basis of social criteria laid down in legislation. The three key criteria are low income, low wealth and need for housing, with priority given to homeless applicants and applicants at risk of eviction. Consequently, the sites in my study resemble each other in socio-economic status: high levels of unemployment, low levels of education, high benefit dependency, and high levels of single mother-headed families. In the Finnish context, both areas are seen as "immigrant areas" despite the fact that $75 \%$ to $85 \%$ of the population are ethnic Finns. In a country that for a long time has remained relatively homogeneous in terms of ethnic composition, even a small ethnic minority presence in urban space seems to evoke a stigmatizing image of disorder (Jensen \& Christensen, 2012, p. 83). This is one part of the complex story of the changing nature of stigma as it touches these neighborhoods.

For five years beginning in 2012 I conducted ethnographic fieldwork (Atkinson, Coffey, Delamont, Lofland, \& Lofland, 2001; Hammersley \& Atkinson, 1983; Jerolmack \& Khan, 2018) in both neighborhoods. I studied daily neighborhood interactions, trying to understand patterns of encounters and interactions in the courtyards, cafes, pubs, supermarkets, libraries, schools, youth centres, community rooms and all other places where locals spent their time. I followed the functions of various neighborhood organizations and associations, attending dozens of public meetings. In addition, I volunteered for neighborhood festivals, a cooking course for local young people and a lunch cafeteria that hired people recovering from substance abuse. Over the course of my fieldwork I came to know a large number of people, most of whom I became familiar with within these contexts. Accordingly, publicly engaged individuals, longtime residents, and people attached to their neighborhood are overrepresented in the sample. With my key informants, I recorded 60 in-depth interviews asking residents to describe their life histories and resident careers, their locally embedded everyday lives, their social networks and relationships, and their understandings of their neighborhoods as physical, social, historical and symbolic places. I also interviewed dozens of people working at local institutions, such as landlords, janitors, teachers, social workers and the police. Interviews took 60 to 200 minutes, were transcribed and coded.

The way Small (2004, p. 196) has described, my approach to data collection can be thought of as "historically informed," since my aim was to interpret the observed present conditions in light of continuously invoked elements of the past. From the beginning of my fieldwork, I was surprised how much the history of the neighborhood colored the way residents saw the world, leaving me no option but to augment my data with knowledge of that history. Thus, I complemented general neighborhood histories with archival data including meeting minutes, action plans, reports, flyers and newspaper clippings that were made available to me by a couple of older local activists, neighborhood associations and city officials. I also studied census and archival records and analyzed 560 newspaper articles from the 1960 s right up to the period of my fieldwork in order to get a picture of stigmatization processes at work in the media. All the data in my research has been translated from Finnish.

The locally emerging place narratives that I turn to next are the product of five years of historically informed ethnography and abductive reasoning (Tavory \& Timmermans, 2014). During my fieldwork, I first noticed that the stories people told about their neighborhood were patterned, linked to the past and interactively reproduced in conversations with others. I then began collecting data on neighborhood histories, realizing that the better I understood the past, the better I understood the lenses through which residents saw the neighborhoods and themselves. The analysis was a back and forth process during which I continually produced new hypotheses based on surprising research evidence.

When describing my data, I talk about "residents" to make my argument, but this does not mean that the neighborhoods were two homogeneous communities. Instead of arguing that everybody in the neighborhoods perceived the areas the same way or recognized every aspect of the place narrative, I argue that residents similarly attached to their neighborhood shared a similar narrative that was context-specific. Further, based on ethnographic work that allowed me to observe patterns of behavior and local interactions, I argue that understanding the locally embedded place narratives gives us insight to comprehend the different ways residents in similar societal positions collectively responded to non-recognition.

\section{Two Neighborhoods, Two Place Narratives}

Fireweed Village and Steephill have always stood and still stand as symbols of social disorder, poverty and nonparticipation-as places for the "have-nots." In line with this narrative, those in power have named and identified these places as "problem neighborhoods." Residents in Fireweed Village and Steephill knew how outsiders saw them and were used to being approached as people of no value. "It is nice place even if outsiders think we are rubbish," a woman living in Steephill said to me, phrasing the widely shared experience in both neighborhoods.

Next, I briefly present the historical context of how the two similarly stigmatized neighborhoods have developed. The origins of their place narratives can be traced to different neighborhood histories that enabled different available cultural repertoires to emerge-one stressing stigmatization based on residents' class position and their difference from the middle-class, the other 
stressing territorial stigma and residents' similarity to the middle-class.

\subsection{Fireweed Village and the Narrative of Class Struggle}

The place narrative of Fireweed Village was a narrative of class struggle. The area was originally built for workingclass families in the 1960s and the people who moved in worked in local factories, at the shipyard and port situated close to the neighborhood, and for the municipality. Most of them had been living in old wooden houses, or in single rooms without indoor toilets or other modern conveniences, so modern homes with kitchens and bathrooms meant huge improvements in their living conditions. The first cohort typically got a job first and after that, their employer provided an apartment in one of the buildings reserved for its employees. An old-timer, Maija, who was a lady in her 60s and whose extended family I became familiar with, had ended up living her life in the neighborhood because her husband had worked for the telephone company, taking care of cables. "The union for local government workers was one of the big owners here, so it was obvious we would get the apartment. All we needed was a certificate of my pregnancy," she reminisced in an interview.

These processes ensured that Fireweed Village was from the days of its construction a distinctively workingclass neighborhood, both in practice and in residents' minds. Social class was one of the central organizing principles of social life, one that on many occasions eclipsed other determinants of group formation and decisively shaped collective experience. The denigration of the newly built public housing neighborhood that soon took hold in local media was interpreted as an attack on working-class people rather than on people living on a public housing estate. In 1970, when local newspapers had been writing about disorder, irresponsible families and badly behaved youths disrupting the area, a resident responded in one of the papers (Kansan Uutiset, 1976):

It is of course profitable for the bourgeois to abuse the working class, and Fireweed Village as a workingclass area is a fantastic target for their ends. Their purpose is to break working-class dignity and cohesion. Therefore, residents of the Village should not yield to attempts to stigmatize their neighborhood, but fight to clear up the facts and put an end to the slandering of their neighborhood.

In the 1970s, working-class dignity and cohesion-the destruction of which the writer was worried aboutwere lived realities; most of the residents participated in a social life organized locally around sports, clubs and societies by leftist political parties. Consequently, social identifications were relatively local and a sense of community among residents easily sustained. From old- timers' stories comes a sense that the idea of social mobility was not something that pervaded their day-to-day lives. They were working-class people and what distinguished them from others was their societal position and the space that was classed as belonging to them.

In the post-industrial community of the 21st century, which Fireweed Village turned into and which I became familiar with, the word "class" was hardly mentioned. Most of the local factories - and the political parties once visible in the neighborhood-were gone. The only actors present were NGOs and occasional projects led by the city, both approaching the neighborhood as a place for the poor. Nevertheless, class consciousness was stored in the place narrative. Residents may not have used the word class any longer, but the sense of we-ness in the narrative of class struggle was still based on the idea of the fixed opposition between "us" - the people who make up the neighborhood, and "them" - the outsiders, who in their privileged position have become estranged from our lives and struggles. In the course of my fieldwork, I observed how the place narrative was transmitted forward, and adopted by newcomers who got involved in local life. Erik, who was a 40-year-old trucker, moved to Fireweed Village with his family and became neighbors with the old-timer Maija mentioned above. They became acquaintances and within a year Erik, who said his first impression of the neighborhood had been "a hellhole," had reformulated his perception about the place. "Work is gone but we (the residents) will not fold. This is a good place. I want my kids to grow up in an environment where nobody looks down on you," he told me in an interview.

\subsection{Steephill and the Narrative of Middle-Class Aspiration}

In Steephill, the place narrative was a narrative of middleclass aspiration. While Fireweed Village was situated close to factories of national importance, Steephill was built in the 1960s far from worksites in the middle of nowhere. People that moved in were janitors, bus drivers, cleaning ladies and nurses. Some, too, were factory workers, but most of them belonged to the class of privatized workers, distancing themselves both from country people and from the traditional working-class. For them, moving to Steephill was an (inevitable) step in their trajectory towards the middle class. Moving from filthy, noisy and cold 20 square meter rooms in the city center to new 60 square meter apartments was concrete proof of imminent upward social mobility.

"We didn't participate in anything here," Eeva told me. She had moved to Steephill at the end of the 1970s when she was expecting her third child. In an interview, she described me how she and her peers had devoted themselves to family and work, not the neighborhood. "There was nothing like that (community activism) since this was a rising neighborhood after all. We just moved here and lived here." 
Families living in Steephill spent hours commuting to work and back, living their lives and trying to make the best of what they had. Politically, residents were to the left, but unlike in Fireweed Village, class consciousness was not a strong source of explicit collective identity. Instead, rapidly growing territorial stigmatization, based on generalized prejudices against public housing, served to draw the residents of Steephill together. In the 1980s, when residents already were used to moral attacks against their neighbourhood, a number of them publicly defended it in the national media. One resident wrote to the newspaper (Helsingin Sanomat, 1989):

Steephill is one of the nicest areas in the city, so much better than its reputation. Its bad reputation is based on unjustified public denigration that has nothing to do with the people living in it. Perfectly ordinary citizens live here.

The resident wanted to correct (from her point of view) unfounded prejudices: Steephill was no different from other areas and was inhabited by people no different from anyone else. Unlike in Fireweed Village, where the place narrative evolved around residents' workingclassness, in Steephill the urge of being like others consisted in aspiration towards the middle class.

Consequently, territorial stigma in the place narrative of middle-class aspiration is not explained by social hierarchies but by outsiders' prejudices against a specific residential area. More than the people living in a place, it is the place itself that generates the stigma. When I interviewed Anna, who had been living in Steephill since 1980s, she explained to me:

The reputation is still like, "Steephill, oh my god, that's terrible," but people who say that don't know what they are talking about. In this neighborhood, we think that the real problem is people who have these wrong ideas. But we know it's not like that, we know how it really is.

In this place narrative, the origin of the sense of we-ness is more in the place than in the people. What outsiders don't know is that Steephill from the point of view of the residents is "in reality" no different from other areas, and it is this consciousness of place that brings residents together. In Steephill being "like-minded" did not mean shared social position but a willingness to stick up for your neighborhood. Unlike in Fireweed Village, where residents tended to point out their position in contrast to that of outsiders, the people of Steephill were more likely to blur the boundary. It made no sense to confront the middle-class since (in line with their place narrative) residents saw themselves as belonging to it-or at least being on the way there.

So it was that, over time, in two places that suffered from very similar housing stigma, different understandings of what kind of people live in those areas came into being. These place narratives, as I will argue, explained the different destigmatization strategies residents collectively employed to cope with practices of non-recognition.

\section{Destigmatization Strategies in Action}

In this section, I turn to ethnographic vignettes describing non-recognition arising as a consequence of interaction of people with unequal relational positions. The vignettes come from community meetings involving residents and outsiders discussing neighborhood matters. In Fireweed, the discussion concerns energy efficiency improvements that had been made in the neighborhood, and that from the perspective of residents, lowered their standard of living. In Steephill, the discussion centres on future relocation of residents living in houses set to be demolished. Rather than these immediate issues, I explore community meetings as examples of routine actions where non-recognition happens as a side effect of other ongoing activities (Lamont et al., 2014). In the course of interaction, residents' sense of co-ownership of place (Brown-Saracino, 2011) is similarly ignored, bypassed and denied in both neighborhoods. This is remarkable considering the decades long activation of residents who, in line with the ideals of participatory democracy, had repeatedly been encouraged to become attached to their residential communities and take part in local decision making (Luhtakallio \& Mustranta, 2017). Nevertheless, the ethnographic vignettes illustrate how residents expecting to have rights towards the neighborhood they belonged to in practice faced invisibility.

Both meetings were processed not just in situ but also outside the meeting rooms, where residents both prepared for the meetings and gave their reactions. A closer look at what happened before and after the meetings reveals that similarly non-recognizing situations were in fact experienced, perceived and interpreted in different ways (see Moon, 2012). Leaning on my ethnography, I suggest that the responses reflected local place narratives that served as a sort of cognitive filter shaping participants' understandings of what happened in the meetings and why. First, let us take a closer look at Fireweed Village residents' responses to a community meeting which was interpreted as confrontation between themselves and outsiders.

\subsection{Community Meeting in Fireweed Village}

In Spring 2013, a community meeting was called jointly by the landlord and the residents' committee. The housing company had recently hired an energy conservation company to lead a year-long project to make the area more energy efficient. The company had installed devices on all the water taps in the neighborhood to slow down the flow of water. Residents had been told that saving energy would mean sacrifices, but that economic savings would be achieved, too. However, they had not been 
happy about the changes to their facilities. "A hot shower is one of the little amenities I can afford, and they are taking it away from me," one woman explained before the meeting. In the invitation to the meeting, residents had been told that a consultant would be there to clarify the rationale behind and aims of the project and to answer their questions. Almost eighty residents turned up.

The (re)configuration of "them" and "us" was present and reproduced before the meeting as residents gathered in front of the building. Many people had come well in advance, forming a crowd in which conflict was fomented through discursive practices. "We'll see whether her majesty [the landlord] has the guts to attend from the beginning. Last time I remember her arriving not until it was her turn to speak," somebody said, making those around him laugh. People collectively recalled meetings that had ended in conflict before, criticizing the landlord and her inability to understand them. They effectively reconstructed an indignation stemming from the social-structural hierarchies that marked their past. Not everybody participated in this us-them reconstruction, of course, but certainly nobody present could dismiss the experience of repression loudly expressed by old-timers and other locally influential residents. When the meeting began, the audience were waiting as quiet as mice.

An energy consultant representing the energy conversation company opened the meeting. He presented a slideshow illustrating the neighborhood's energy consumption in complex figures, but soon the audience grew restive. The graphics illustrating correlations between decreased energy consumption and savings at the local level provided no answer to the problems inconveniencing them in their everyday lives: cold apartments and low water pressure. Joni, the 36-year-old chair of the residents' association, interrupted the consultant from the front row: "Now that you have installed these gadgets all over the place, when exactly are we going to see the results?"

The consultant explained that he would only be able to say anything for certain after a couple of years. A man sitting at the back cried out: "But by then we'll have been paying for this craziness for three years!" He verbalized the experience shared by the people around him who perceived the project as a collective investment supported by the residents. The audience wanted to know when and how the promised savings of the project would materialize. "There goes our fucking money," somebody complained.

At this point, the landlord stood up: "You need to remember that you are only renting your properties, while we need to secure the future of this company." There was of course nothing incorrect in her argument, since the owner of the company was the one responsible for decision-making. Nevertheless, her framing of the situation discounted residents' concerns along with their experiences and expressions of co-ownership of the place. Even though they were "just renting," residents approached the place as their own.
After the community meeting, we slowly spilled out into the cold March evening. Most of the residents began to head home, bidding each other good night and commenting on the meeting in words that reflected their collective irritation. "Who does he think he is, coming here and telling us he knows how we feel?" somebody said. "Well, this was another of those meetings," said another. Not everybody was in a hurry, however, and at least fifteen of us stayed in the yard, lighting cigarettes and gathering into smaller groups of two to five people. Everybody was talking about the meeting. I stood there with an older lady who had been living in the neighborhood since the 70s. "How did it go?" I asked her. "Well," she said, taking a long drag on her cigarette: "Just like these meetings always are. Nothing ever changes, because everything has already been decided in advance. We only come here to listen to what they have to say." A man I did not know who had been standing close to us turned and observed laconically: "Masters decide, we whine." People around him burst into collective laughter. Understanding the situation through the lens of the narrative of class struggle empowered residents, enabling them to collectively work on their emotions. This was a different strategy from that at Steephill, where the roots of collective destigmatization strategy lay in the place narrative of middle-class aspiration.

\subsection{Community Meeting in Steephill}

A year later in 2014, I observed a community meeting in Steephill where, as part of a ten-year-long reconstruction project, a number of buildings were to be demolished. The landlord had called a meeting to inform residents of the schedule and give details of the demolition project only four months before they were due to leave their homes. Uncertainty about the project had preyed on residents' minds, since they were unaware of the location of their temporary accommodation and whether they could move back to the estate or not. The practices of non-recognition during the meeting were similar to those at the meeting in Fireweed Village, but the way residents both collectively prepared for the meeting and responded to it afterwards was different.

Before the meeting began, the landlord sat in front of the audience in conversation with the architect who had made the plans for the new buildings. Beside them, behind a long table, were two young women from the house management agency responsible for the practicalities of relocating the residents. An official working for the city sat with them; her role was to explain how residents were to be selected. The audience of around 80 residents arrived between five and ten minutes before the meeting. The atmosphere was expectant, but not at all hostile. Most residents had been looking forward to the meeting. "I don't care where I go as long as I get the new [apartment]...a year or two somewhere else, at this age, it's all the same, but once I get back I'll only be carried out in a box," one of the two ladies chatting next to 
me said cheerfully. The other echoed her, saying that she believed "it's all been taken care of." Their conversation was interrupted by a third lady who swept into the room, took the seat that the two had been reserving for her, and expressed her hope that the meeting would be over before her favorite TV series. "It's too exciting to miss," she said. As the landlord finally took the floor, he had to clear his throat several times before the audience settled down to listen to him. There was no sign of organized opposition, as the residents cheerfully chatted about their everyday business.

Compared to the meeting in Fireweed Village, the interaction at Steephill followed a very similar pattern. Residents expressed ownership of the place and felt that they had already paid for the rebuilding with rent rises, whereas the outsiders reminded them of their status as mere renters of the apartments. The subject came up towards the end of the meeting as the landlord asked everybody who wanted to move back to Steephill to raise their hands. Almost everybody did. A longtime resident wanted to know what meant the expression of old residents having "priority" to move back. "It means that we may not be able to return, right?" he inquired. The officer representing the committee to choose the new residents answered: "Yes, the final decisions are always made in the committee." Then she gave a long account of the principles according to which the committee makes decisions, but without referring to this particular case, leaving residents uncertain as to whether they could move back to their homes or not. The audience expressed disquiet, given that this information was the very reason they had come to the meeting in the first place.

One resident took the floor: "But we have already paid for the rebuilding, since that's why you raised the rents in the first place," he said. The landlord sighed: "But if you're renting, it's not your money. The owner of the property has the right to use the money as they like." He moved away from the subject and said that most of the current two-room apartments would be replaced with three-room apartments, so "either way, you will probably not get the same kind of apartment you left." Then he added: "Besides, some might not even want to move back, or if their life situation has changed, some might even want the three bedrooms." One man became angry: "Yeah, and some might win the lottery, too. We probably can't afford to come back." The landlord began to lose patience. As a resident begun saying that "you have been using our money...," he interrupted saying: "Nobody has personal accounts here. The money is common money."

After the meeting everybody rushed outside. There, residents asked each other whether anybody had received information on when and where they would be moving. However, nobody had. One might expect that the frustration caused by this uncertainty would have spilled over; but nothing happened. Instead, residents smoked their cigarettes and talked about the detailed reconstruction plans presented at the beginning of the meeting: "What I'm wondering is whether they're go- ing to knock down every tree around here," a man said. "As far as I could tell, the new apartments looked really nice," one woman said. "I suppose the architect man there didn't quite know what he was doing. I just think he didn't know the place where he's going to put the new buildings," she reasoned. By talking about their knowledge of a place that the planners were not thoroughly familiar with, the residents underlined their ownership of the place, at the same collectively ignoring the fact that their rights with respect to it had just been questioned. If there was anger, it was active only on the individual level; collectively, the residents' strategy for dealing with nonrecognition was to understate-almost ignore-it. They simply refused to assume the position of powerlessness that outsiders were trying to impose on them.

\subsection{Becoming Persons of Value}

Strategies for coping with non-recognition in the two neighborhoods were different in the residents' meetings described above, as they were in the other encounters with outsiders I observed during my fieldwork. The narrative of class struggle in Steephill produced a repertoire of confrontation residents turned to when perceiving nonrecognition. In contrast, the narrative of middle-class aspiration produced a repertoire of negotiation that enabled residents to rationalize the situations and suppress their stigmatized position. Both of these collective level strategies to respond to non-recognition allowed people to protect their sense of dignity and become persons of value. According to Lamont and Mizrachi (2012, p. 372) members of stigmatized groups appear to confront the tension between emotional outcomes resulting from stigmatization (anger, feelings of worthlessness, loss of dignity) on the one hand and the need to gain recognition as an individual and as a member of a group on the other. In Fireweed Village, the residents' strategy for constructing dignity was to highlight their oppressed class-position, mutual equality and sense of pride. Conforming the meeting to their narrative of place, their self-esteem remained unscathed by outsiders' non-recognizing behavior-even if perceived as unjust. In Steephill, conversely, residents refused to represent themselves as victims or reproduce a class division, this way maintaining their dignity and preserving control over their own lives. In their perceived equality with everyone else they remained untouched, even if non-recognized on the basis of their place of residence.

\section{Conclusion}

The topics discussed in the community meetings in the neighborhoods in my study serve specifically to confirm my argument. In Fireweed Village, where the place narrative of class struggle worked as a cultural resource for dealing with non-recognition, the participants discussed the inconvenience of low water pressure. Meanwhile in Steephill, where the place narrative of middle-class as- 
piration was present, residents were told to leave their homes and forced to live in uncertainty as to whether they could move back or not. The significance of the topic under discussion was much smaller in Fireweed Village, and yet the collective response was stronger. This suggests that the cultural repertoires people turn to when making sense of their experiences are interconnected with the larger matrix of relationships and stories that shape their lives.

In this article, I have focused on neighborhoodlevel repertoires suggesting that in two similar social housing neighborhoods residents' collective interpretations and habitual responses to similar practices of nonrecognition were related to locally constructed and historically formed place narratives. These narratives mattered because they were stories residents identified with, informing their understandings of both themselves and their relations to others. In Fireweed Village, where the remnants of its politically charged working-class background still pervaded the cultural milieu of the neighborhood, residents approached the meeting more as a opposition between "us-the oppressed" and "them-the oppressors," whereas in Steephill, where consciousness of a shared social position had never really gained a footing, rather than highlighting their unequal position residents seemed to trivialize it. In terms of their social structural positions, residents' stigma consciousness (Pinel, 1999) differed in that in Fireweed Village residents expected to be stereotyped by others based on their class position, whereas in Steephill they did not. Thus, neighborhoods that appeared similar in statistics and in their positions on urban margins diverged in their collective experiences of classed selves.

Consequently, destigmatization strategies varied across places because despite their statistical similarities their cultural milieus differed. The empirical findings of my study suggest that first, stigmatization in terms of social housing should also be understood as taking the subtle forms of non-recognition. Second, the identities people use to makes sense of non-recognition change salience in response to the places and their narratives. And third, the collective nature of destigmatization strategies has hitherto been underestimated.

\section{Acknowledgments}

I would like to thank the editors of the thematic issue and the anonymous reviewers for their helpful comments on this article. I also thank the members of the Center for Sociology of Democracy for valuable comments on an earlier version of this article. This work was conducted with support from the Academy of Finland and Kone Foundation.

\section{Conflict of Interests}

The author declares no conflict of interests.

\section{References}

Arthurson, K., Darcy, M., \& Rogers, D. (2014). Televised territorial stigma: How social housing tenants experience the fictional media representation of estates in Australia. Environment and Planning A: Economy and Space, 46(6), 1334-1350.

Atkinson, P., Coffey, A., Delamont, S., Lofland, J., \& Lofland, L. (2001). Handbook of ethnography. London: SAGE.

August, M. (2014). Challenging the rhetoric of stigmatization: The benefits of concentrated poverty on Toronto's Regent Park. Environment and Planning $A$, 46, 1317-1333.

Binken, S., \& Blokland, T. (2013). Everyday encounters in public spaces: Findings from Rotterdam and Utrecht. In M. Kusenbach \& K. E. Paulsen (Eds.), Home. International perspectives on culture, identity, and belonging (pp. 293-311). Frankfurt am Main: Peter Lang.

Blokland, T. (2008). "You got to remember you live in public housing": Place-making in an American housing project. Housing, Theory and Society, 25, 31-46.

Blokland, T. (2009). Celebrating local histories and defining neighbourhood communities: Place-making in a gentrified neighbourhood. Urban Studies, 46(8), 1593-1610.

Blokland, T. (2017). Community as urban practice. Cambridge: Polity Press.

Borer, M. I. (2006). The location of culture: The urban culturalist perspective. City \& Community, 5(2), 173-197.

Brown-Saracino, J. (2011). From the lesbian ghetto to ambient community: The perceived costs and benefits of integration for community. Social Problems, 58(3), 361-388.

Brown-Saracino, J. (2015). How places shape identity: The origins of distinctive LBQ identities in four small U.S. cities. American Journal of Sociology, 121(1), 1-63.

Cole, I. (2013). Whose place? Whose history? Contrasting narratives and experiences of neighborhood change and housing renewal. Housing, Theory and Society, 30(1), 65-83.

Fine, G. A. (2012). Group culture and the interaction order: Local sociology on the meso-level. Annual Review of Sociology, 38, 159-179.

Fraser, N. (1997). Justice interruptus: Critical reflections on the "postsocialist" condition. New York, NY: Routledge.

Garbin, D., \& Millington, G. (2012). Territorial stigma and the politics of resistance in a Parisian banlieu: La Courneuve and beyond. Urban Studies, 49(10), 2067-2983.

Gotham, K. F., \& Brumley, K. (2002). Using space: Agency and identity in a public-housing development. City \& Community, 1(3), 267-289.

Hammersley, M., \& Atkinson, P. (1983). Ethnography: Principles in practice (2nd ed.). London: Routledge. 
Hastings, A. (2004). Stigma and social housing estates: Beyond pathological explanations. Journal of Housing and the Built Environment, 19(3), 233-254.

Helsingin Sanomat. (1989, September). Letters from the readers. Helsingin Sanomat.

Hyötyläinen, M. (2019). Divided by policy. Urban inequality in Finland (Unpublished Doctoral Dissertation). University of Helsinki, Finland.

Jensen, S. Q., \& Christensen, A.-D. (2012). Territorial stigmatization and local belonging. City, 16(1/2), 74-92.

Jerolmack, C., \& Khan, S. (Eds.). (2018). Approaches to ethnography. Analysis and representation in participant observation. New York, NY: Oxford University Press.

Junnilainen, L. (2019). Lähiökylä. Tutkimus yhteisöllisyydestä ja eriarvoisuudesta [A place where you matter. Communality and inequality in public housing neighborhoods]. Tampere: Vastapaino.

Kansan Uutiset. (1976, August). Letters from the readers. Kansan Uutiset.

Kirkness, P. (2014). The cités strike back: Restive responses to territorial taint in the French banlieues. Environment and Planning A, 46, 1281-1296.

Kusenbach, M. (2013). Place feelings and life stories in Florida mobile home communities. In M. Kusenbach \& K. E. Paulsen (Eds.), Home. International perspectives on culture, identity, and belonging ( $\mathrm{pp}$. 199-224). Frankfurt am Main: Peter Lang.

Lamont, M. (2018). Addressing recognition gaps: Destigmatization and the reduction of inequality. American Sociological Review, 83(3), 419-444.

Lamont, M., Beljean, S., \& Clair, M. (2014). What is missing? Cultural processes and causal pathways to inequality. Socio-Economic Review, 12(3), 1-36.

Lamont, M., \& Mizrachi, N. (2012). Ordinary people doing extraordinary things: Responses to stigmatization in comparative perspective. Ethnic and Racial Studies, 35(3), 365-381.

Lamont, M., Silva, G. M., Welburn, J. S., Guetzkow, J., Mizrachi, N., Herzog, H., \& Reis, E. (2016). Getting respect: Responding to stigma and discrimination in the United States, Brazil, and Israel. Princeton, NJ: Princeton University Press.

Lamont, M., \& Small, M. L. (2008). How culture matters: Enriching our understandings of poverty. In D. Harris \& A. Lin (Eds.). The colors of poverty: Why racial and ethnic disparities persist (pp. 76-102). New York, NY: Russell Sage Foundation.

Link, B. G., \& Phelan, J. C. (2001). Conceptualizing stigma. Annual Review of Sociology, 27, 363-385.

Link, B. G., \& Phelan, J. C. (2014). Stigma power. Social Science \& Medicine, 103, 24-32.

Luhtakallio, E., \& Mustranta, M. (2017). Demokratia suomalaisessa lähiössä [Democracy in a Finnish suburb]. Helsinki: Into.

Mckenzie, L. (2015). Getting by. Estates, class and culture in austerity Britain. Bristol: Policy Press.
Moon, D. (2012). Who am I and who are we? Conflicting narratives of collective selfhood in stigmatized groups. American Journal of Sociology, 117(5), 1336-1379.

Palmer, C., Ziersch, A., Arthurson, K., \& Baum, F. (2004). Challenging the stigma of public housing: Preliminary findings from a qualitative study in South Australia. Urban Policy and Research, 22(4), 411-426.

Pereira, V. B., \& Queirós, J. (2014). "It's not bairro, is it?": Subsistence sociability and focused avoidance in a public housing estate. Environment and Planning $A$, 46, 1297-1316.

Pescosolido, B., \& Martin, J. (2015). The stigma complex. Annual Review of Sociology, 41(1), 87-116.

Pinel, E. C. (1999). Stigma consciousness: The psychological legacy of social stereotypes. Journal of Personality and Social Psychology, 76, 114-128.

Queirós, J., \& Pereira, V. B. (2018). Voices in the revolution: Resisting territorial stigma and social relegation in Porto's historic centre (1974-1976). The Sociological Review Monographs, 66(4), 857-876.

Reed, I. A. (2017). On the very idea of cultural sociology. In C. E. Benzecry, M. Krause \& I. A. Reed (Eds.), Social theory now (pp. 18-41). Chicago, IL: The University of Chicago Press.

Ruonavaara, H. (1996). The home ideology and housing discourse in Finland 1900-1950. Housing Studies, 11(1), 89-104.

Scott, J. C. (1985). Weapons of the weak: Everyday forms of peasant resistance. New Haven, CT: Yale University Press.

Sharkey, P., \& Faber, J. W. (2014). Where, when, why, and for whom do residential contexts matter? Moving away from the dichotomous understanding of neighborhood effects. Annual Review of Sociology, 40, 559-579.

Skeggs, B. (2004). Class, self, culture. London: Routledge.

Slater, T. (2018). The invention of the 'sink estate': Consequential categorisation and the UK housing crisis. The Sociological Review, 66(4), 877-897.

Slater, T., \& Anderson, N. (2012). The reputational ghetto: Territorial stigmatisation in St Paul's, Bristol. Transactions of the Institute of British Geographers, 37(4), 530-46.

Small, M. L. (2004). Villa Victoria. The transformation of social capital in a Boston barrio. Chicago, IL: University of Chicago Press.

Somers, M. (1994). The narrative constitution of identity: A relational and network approach. Theory and Society, 23(5), 605-649.

Tavory, I., \& Timmermans, S. (2014). Abductive analysis. Theorizing qualitative research. Chicago, IL: The University of Chicago Press.

Tyler, I., \& Slater, T. (2018). Rethinking the sociology of stigma. The Sociological Review, 66(4), 721-743.

Vassenden, A., \& Lie, T. (2013). Telling others how you live-Refining Goffman's stigma theory through an analysis of housing strugglers in a homeowner nation. 
Symbolic Interactionism, 36(1), 78-98.

Wacquant, L. (2007). Territorial stigmatization in the age of advanced marginality. Thesis Eleven, 91(1), 66-77.

Wacquant, L. (2008). Urban outcasts: A comparative sociology of advanced marginality. Cambridge: Polity Press.

Wacquant (2011). Territorial stigmatization revisited: Symbols, state, and space. Paper presented at the International Conference on Territorial Stigmatiza- tion and Advanced Marginality, University of Porto, Portugal.

Wacquant, L., Slater, T., \& Pereira, V. B. (2014). Territorial stigmatization in action. Environment and Planning $A$ : Economy and Space, 46(6), 1270-1280.

Wassenberg, F. (2004). Large social housing estates: From stigma to demolition? Journal of Housing and the Built Environment, 19(3), 223-232.

\section{About the Author}

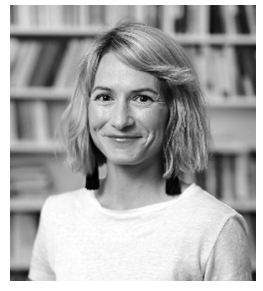

Lotta Junnilainen is a Sociologist and urban ethnographer, working as a postdoctoral researcher at Tampere University, Finland. Her research interests lie in the area of urban inequality, class, place and belonging. She received her PhD from the University of Helsinki in 2019. Her dissertation, an ethnographic study of two social housing neighbourhoods in Finland, was also published as a book. Junnilainen is currently working on "BIBU-Tackling Biases and Bubbles in Participation" (bibu.fi), a project funded by the Strategic Research Council at the Academy of Finland. This research examines the relationship between class, space and politics. 